\title{
A new look at world class physical asset management strategies
}

\author{
I.B. Hipkin \\ School of Management Studies, University of Cape Town, Private Bag, Rondebosch, 7700 Republic of South Africa
}

Received June 1998

\begin{abstract}
The need for enhancing manufacturing systems is increasing, with growing attention on the management of physical assets. This has arisen because of a number of new pressures, such as stringent cost control, automation requiring higher availability and reliability from equipment, and greater attention being paid to safety and environmental issues. This study (following the general approach adopted by Meredith) considers some new maintenance thinking, which has been summarised as a series of postulates. These postulates are analysed as a theory building exercise by referring to a number of case organisations to assess their wider applicability and relevance in physical asset management. The study concludes that there is general acceptance of the new maintenance thinking.
\end{abstract}

\section{Introduction}

Companies are increasingly looking to new management interventions to bring about improvements in their operations. Claims and counter-claims persist as to the effectiveness of the three-letter acronyms, such as TQM, BPR, JIT and so on, and what has gone right and wrong in their implementation. Impressive reports of vast cost reductions and improvements in output and quality are countered by scepticism and refutation.

The profound changes taking place in the operations field are increasingly incorporating the maintenance function. This is essentially because of the increasing demands being brought upon physical assets through stricter safety, environmental and cost control measures, greater reliance on technology and automation to increase output, and because of the role maintenance plays in achieving and retaining competitive quality standards. In addition, some fundamentally new approaches to the management of physical assets are emerging. It is becoming increasingly important to understand how equipment functions and the implications of its failure. More data, information and knowledge are essential if engineers and managers are to attain a full technical and operational understanding of their plant, equipment and processes. Information technology is being called upon to assist in achieving an increasingly broad range of objectives in the management of physical assets.

Developments in maintenance management information systems have meant a steady move away from the traditional planning and scheduling of maintenance aetivities to expert maintenance management information systems which support the implementation of current maintenance philosophies, such as reliability-centred maintenance (RCM) and total productive maintenance (TPM).

This article looks at some of the new thinking in physical asset management which is assisting organisations in progressing from leaders in their industries to world class companies, and considers some of the processes which establish the technical and environmental factors which will provide greater understanding of maintenance management systems and technologies.
Using the case study approach (McCutcheon \& Meredith, 1987; Meredith, 1987; Yin, 1989) as a theory building mechanism (Eisenhardt, 1989; Flynn et al., 1990), this study uses the literature and the results of research into a number of case organisations to test the findings postulated by the theoretical considerations.

\section{A closer look at some new maintenance thinking}

The term physical asset management is frequently used synonymously with maintenance management, although the former term encompasses a broader range of activities and applications. Maintenance invokes the notion of factory plant and equipment, which is predominantly, but by no means exclusively, related to rotating equipment. Physical asset management incorporates the traditional maintenance sphere of activities, but also includes buildings and structures, many of which have no relationship with production activities.

Manufacturing organisations have been compelled to look at their physical asset management for several reasons: increased competition has demanded strict cost control, with maintenance accounting for an increasing share of operational costs (Paz \& Leigh, 1994); safety and environmental disasters are increasingly attributable to equipment failure; maintenance itself is changing, with some substantially different ways of understanding the nature of failure; automated facilities require higher availability and reliability from plant and equipment (Moubray, 1997). The purpose of maintenance has generally been perceived as preventing failures to attain adequate availability and reliability (Banerjee \& Flynn, 1987; Bennett \& Jenney, 1980). For several reasons, these are seldom defined in quantitative terms: the mathematical analysis of many modern systems is too complex (Banerjee \& Flynn, 1987); the information required is seldom available in a usable form (Christer, 1984; Huber, 1984); low priority is ascribed to such quantification (Turban, 1967); and many organisations lack historical data (Currie \& Sneddon, 1992), having only simple, subjective methods of integrating failure and performance data (Bennett \& Jenney, 1980).

In seeking to minimise maintenance costs, preventive maintenance systems have provided for regular intervention based on predetermined maintenance intervals. A survey of the 
quantitative literature (Cho \& Parlar, 199I) discusses theoretical and mathematical maintenance and replacement models which are intended to lead to optimal maintenance intervals. These are seldom useful to practitioners as they are frequently chosen to correspond with current modelling practice or are selected for computational convenience (Flynn, Sakakibara, Schroeder, Bates \& Flynn, 1990: 251). The validity of these intervals is now being questioned.

The establishment of maintenance intervals is dependent firstly on the nature of the proposed intervention, and secondly on the nature of the failure itself. The fallacious belief that the severity of consequences of failure should determine the frequency of condition monitoring is replaced by the notion that this interval is governed by lead time to failure (that is, the warning period between when an item's potential failure is first detected and when it is actually no longer capable of fulfilling its function) (Moubray, 1997). Cyclical overhaul or replacement of components is only appropriate if there is indeed a relationship between the age of the component and its probability of failure. This has a profound effect on maintenance policies, especially since it is now widely accepted that most failures are not age related (Moubray, 1997; Smith, 1993). Testing of protective functions (which are hidden, in RCM terminology) is dependent on the exponential relationship which exists between the availability required of the system and its reliability.

Conditions such as management commitment, appropriate support systems and managing resistance to change are necessary for success in any management intervention (Meredith, 1987; Doll \& Vonderbremse, 1991; Padmanabhan \& Souder, 1994) and apply as much to other management interventions, such as total quality management and business process reengineering as to maintenance. Without appropriate infrastructure there can be no formal monitoring and measurement of objectives (Doll \& Vonderbremse, 1991; Geisler \& Rubenstein, 1987; Huber, 1984). The maintenance function also suffers from inadequate performance reporting systems (Bouche, Plauchu \& Retour, 1986; Currie \& Sneddon, 1992; Drucker, 1990). Support for a new technology also implies adequate training for participants (Crawford \& Blackstone, 1988; Safayeni \& Purdy, 1991), even though training is not sufficient to ensure skill of use (Leonard-Barton, 1987). Much of the TPM philosophy is directed at addressing these conditions.

Competitive advantage is increasingly obtained through knowledge and the knowledge-based company (Leonard-Barton, 1995). For a number of years, this concept has had a direct bearing on maintenance: knowledge of machine capabilities, a thorough understanding of the production process, and a high level of production competence are essential before maintenance requirements can be determined (Jaikumar, 1986; Cleveland et al., 1989; Ferdows \& De Meyer, 1990). Understanding functionality is now a central theme of maintenance. Indeed, the task of maintenance now becomes that of ensuring functionality (Gits, 1994), rather than simply preventing failures. Inability to sustain functionality therefore constitutes the failed state, which now requires a precise definition. It is only possible to distinguish between functional and failed states if performance standards have been quantified in the operating context under consideration (Moubray, 1997). Additional information is frequently required which relates to failures, and this is usually contained in a maintenance management information system (MMIS).

An MMIS is 'good' if it contains a comprehensive history database. The belief is widespread that without a large database, preventive maintenance cannot be undertaken. Further. MMISs fall into disrepute as they do not apparently improve maintenance. Production managers feel that maintenance intervention is unnecessary; maintenance managers believe that they do not do enough maintenance. It is often hoped that somehow the MMIS will solve this intractable difference in opinion. The problem is often that inappropriate maintenance is undertaken: items which do not have an age-related failure pattern are replaced at regular intervals; condition-based maintenance intervals are determined on a fundamentally incorrect premise. The main problem is not the maintenance task itself, but rather the frequency at which this is undertaken. The MMIS should be tailored and used to provide the correct answers, in à user-appropriate manner.

The quantity of data in an MMIS can be deceptive. If a database contains large numbers of instances where replacements of items are recorded, this does not necessarily mean that the items actually failed. If they did fail, then the interval is probably too short, and so the preventive maintenance system is not achieving what it should. If it is not recorded whether or not items have failed, then the maintenance manager has no way of knowing whether maintenance is excessive. It is often engineering judgement and operational experience which provide the best insight of failure patterns (Moubray, 1997).

The following points summarise the thinking which has been presented in the preceding paragraphs:

1. Maintenance needs to be broadened to incorporate all aspects of physical asset management.

2. Expectations of the maintenance function are changing dramatically.

3. Maintenance is no longer merely about preventing failures.

4. Maintenance is about sustaining functionality.

5. The correct frequency of maintenance intervention is of crucial importance in achieving maintenance objectives.

6. Management commitment and support systems, including an MMIS, are necessary for successful physical asset management.

\section{Case study investigation as a theory building exer- cise}

The above six points were selected from the literature as constituting some of the new thinking in physical asset management. Following the methodology of McCutcheon \& Meredith (1987), Meredith (1987), Eisenhardt (1989) and Flynn et al. (1990), this section describes an initial attempt at theory building by presenting the above points as postulates and testing these in a case study environment.

The 19 organisations used in the study were selected as companies which had completed a major maintenance change programme within the last eighteen months. The organisations are based in the United Kingdom, where the author personally observed the maintenance interventions, arranged the scoring of the postulates, and conducted the interviews. An attempt was made to obtain a cross-section of maintenance 
Table 1 Breakdown of maintenance programmes in sample

\begin{tabular}{lcc}
\hline $\begin{array}{l}\text { Maintenance } \\
\text { intervention }\end{array}$ & $\begin{array}{r}\text { Number of companies and } \\
\text { percentage of total (\%) }\end{array}$ \\
\hline RCM & 8 & $(42 \%)$ \\
TPM & 4 & $(21 \%)$ \\
MMIS & 3 & $(16 \%)$ \\
Other change programmes, & 4 & $(21 \%)$ \\
reviews, etc. & & \\
\hline
\end{tabular}

interventions in order to assess the extent which the postulates were widely applicable. The number of organisations involved in the various maintenance activities is shown in Table 1.

Maintenance managers in the 19 organisations were asked to score the extent to which the postulates were important in achieving excellent or world class maintenance. After scoring the postulates, managers were interviewed to obtain their opinions regarding the factors. The results of the scoring process are shown in Table 2 , which indicates the industry sector of the organisation, the nature of the maintenance implementation and the scores on a five-point Likert scale.

Table 2 shows that there is general concurrence that the postulates are true of current maintenance practice. Although the sample is small, it is interesting to discuss certain aspects which could form the basis of further, more detailed research. The physical asset management postulate was scored the low. est (3.2) indicating positive, but unenthusiastic overall support. However, the three sectors with structures and extensive non-equipment assets (utilities, rail) all scored 5 for this postulate; managers from the two refineries also scored this postulate highly (score 4). This is to be expected, and the point was reinforced in subsequent interviews with respondents who indicated that non-equipment, infrastructural assets required increasing attention.

The second postulate (changing expectations of maintenance) received the second lowest score (3.7). Here the scores of those companies that introduced RCM (scoring 4 or 5 ) differ from those taking the TPM route (with scores 2 or 3 ) The choice of maintenance approach will to some extent affect the thinking of people: TPM does not explore the different requirements of maintenance to a great extent, whereas RCM specifically address the consequences of failure, and thereby looks at a broader range of issues which occur in the event of failure. No specific view or trend is evident in the scores of the organisations that introduced MMISs or conducted general maintenance reviews. Subsequent interviews revealed that maintenance managers were increasingly concerned about the impact of equipment failure on the environment and on safety. The chemical company

\begin{tabular}{|c|c|c|c|c|c|c|c|c|}
\hline & \multirow[t]{2}{*}{ Industry } & \multirow{2}{*}{$\begin{array}{l}\text { Nature of maintenance } \\
\text { implementation }\end{array}$} & \multirow{2}{*}{$\begin{array}{c}1 \\
\text { Physical } \\
\text { asset } \\
\text { manage- } \\
\text { ment }\end{array}$} & \multirow{2}{*}{$\begin{array}{c}2 \\
\begin{array}{c}\text { Expectations } \\
\text { of }\end{array} \\
\text { maintenance are } \\
\text { changing }\end{array}$} & \multirow{2}{*}{$\begin{array}{c}3 \\
\text { Knowiedge of } \\
\text { plant/equipment } \\
\text { essential for } \\
\text { maintenance }\end{array}$} & \multirow{2}{*}{$\begin{array}{c}4 \\
\text { Maintenance } \\
\text { is about } \\
\text { sustaining } \\
\text { functionality }\end{array}$} & \multirow{2}{*}{$\begin{array}{c}5 \\
\\
\text { Correct } \\
\text { frequencies } \\
\text { are } \\
\text { essential }\end{array}$} & \multirow{2}{*}{$\begin{array}{c}6 \\
\\
\text { Support } \\
\text { systems/ } \\
\text { MMIS are } \\
\text { important }\end{array}$} \\
\hline & & & & & & & & \\
\hline A & Paper & RCM & 3 & 4 & 5 & 4 & 4 & 3 \\
\hline $\mathbf{B}$ & Paper & MMIS & 3 & 4 & 4 & 5 & 4 & 4 \\
\hline C & Food & TPM & 2 & 3 & 3 & 3 & 4 & 4 \\
\hline D & Food & RCM & 3 & 4 & 5 & 5 & 4 & 3 \\
\hline $\mathbf{E}$ & Food & MMIS & 2 & 3 & 4 & 4 & 5 & 5 \\
\hline $\mathbf{F}$ & Food & Review of all activities- & 3 & 3 & 3 & 4 & 4 & 4 \\
\hline G & Chemical & RCM & 4 & 5 & 5 & 4 & 4 & 3 \\
\hline H & Chemical & MMIS & 3 & 4 & 3 & 4 & 4 & 5 \\
\hline 1 & Chemical & Review of schedules & 2 & 4 & 4 & 3 & 4 & 4 \\
\hline J & Refinery & RCM & 4 & 5 & 5 & 5 & 4 & 3 \\
\hline $\mathbf{K}$ & Refinery & TPM & 4 & 3 & 3 & 4 & 4 & 4 \\
\hline $\mathbf{L}$ & Motor & TPM & 2 & 2 & 3 & 2 & 4 & 3 \\
\hline M & Motor & RCM & 3 & 4 & 5 & 4 & 4 & 4 \\
\hline $\mathbf{N}$ & Motor & New system & 3 & 3 & 4 & 3 & 4 & 5 \\
\hline $\mathrm{O}$ & Pharmaceutical & $\mathrm{RCM}$ & 2 & 4 & 5 & 5 & 4 & 3 \\
\hline $\mathbf{P}$ & Pharmaceutical & TPM & 2 & 2 & 3 & 2 & 4 & 4 \\
\hline $\mathbf{Q}$ & Rail & RCM & 5 & 5 & 5 & 5 & 4 & 4 \\
\hline $\mathbf{R}$ & Utility & Review of all activities & 5 & 4 & 4 & 5 & 3 & 4 \\
\hline \multirow[t]{2}{*}{$\mathbf{S}$} & Utility & RCM & 5 & 5 & 5 & 5 & 4 & 4 \\
\hline & Average & & 3.2 & 3.7 & 4.1 & 4.0 & 4.0 & 3.8 \\
\hline \multicolumn{9}{|c|}{$1=$ strongly disagree (not at all important) } \\
\hline $5=$ & rongly agree (mo & st important) & & & & & & \\
\hline
\end{tabular}


which scored 5 for this postulate had recently had a fatality which was directly attributable to inadequate maintenance. During its RCM implementation the refinery which had scored 5 for this postulate had discovered an incorrect temperature setting on a compressor which could have had catastrophic consequences. It was generally agreed that this postulate correctly indicated that maintenance is more than repairing items when they fail.

A similar pattern is evident for postulate 3 (the importance of knowledge in maintenance), which receives the highest score (4.1). High scores would be expected for RCM users (5 in all cases) as the RCM approach begins with quantification of performance standards and relating these to plant capability, and failure modes and effects analyses. TPM users scored 3 or 4 for this postulate suggesting that TPM does not consider knowledge as an unduly significant factor in maintenance. Maintenance managers frequently mentioned that without detailed knowledge of the plant and its processes, it was not possible to set an effective maintenance programme. Several acknowledged that their maintenance had been poor because they were not sure of the standards to which they should be maintaining plant: they were not aware of precise performance standards and of the nature of failure. Postulate 4 (maintenance is sustaining functionality) received an average score of 4.0. There was a greater spread of opinion with regard to maintenance as a tool for sustaining functionality, where RCM emphasis is illustrated by the 5 scores, whereas the organisations which had implemented TPM scored twos and threes. The TPM companies' scores are explained by the TPM insistence on 'zero defects' (Nakajima, 1988; Willmott, 1994). These opinions are perhaps not as diverse as they first seem: RCM suggests that maintenance is not about preventing failures, but about avoiding the consequences of failure; in its quest for zero defects, TPM is effectively seeking functionality of plant. However the latter could be interpreted as a command for carrying out maintenance at all costs and in all operating conditions, which is clearly not sensible if no production loss is suffered and no secondary damage is incurred.

The average score for postulate 5 (importance of correct maintenance frequencies) was 4.0 and the individual scores reveal the greatest uniformity. In subsequent interviews managers indicated that while the importance of this postulate was unquestionable, they had great difficulty in determining maintenance intervals. It was evident that in many instances, the bases for determining the frequency of maintenance were incorrect.

The importance of the management support and MMIS postulate is recognised particularly by the organisations who have implemented an MMIS (score 3.8); otherwise there is a broad spread of opinion regarding this postulate. Some managers accepted that precise information would never be readily available in their organisations, so no matter how good their information system, the overall uncertainty of the data with which they work would ultimately be seen as detracting from the effectiveness of the system.

Since the sample has a larger number of companies that implemented the RCM methodology, it is to be expected that the postulates relating to knowledge and functionality will be scored highly. Respondents were adamant that once they had been made aware of the importance of these issues, there could be no doubt as to their significance in maintenance.

\section{How does this new thinking help to improve mainte- nance?}

Maintenance managers are under tremendous pressure to increase plant availability (uptime) and reduce maintenance costs. Any reductions in scheduled maintenance which requires plant stoppages are welcomed. Indeed, managers are always looking for maintenance techniques which promise to reduce scheduled'maintenance and reduce maintenance costs. The problem arises when managers are asked to justify any additional expenditure on new maintenance interventions before implementation, or to explain what the benefit of these has been after implementation.

Frequently the systems are simply not in place to measure the effects of changes in maintenance practice. An MMIS may assist in this, but the challenge for managers is to discipline their staff to use such systems correctly. RCM and TPM are presented as ways in which maintenance can be improved. Both have their limitations, and these should be recognised, otherwise the benefits which they can undoubtedly bring are dismissed because of issues which have nothing to do with RCM and TPM. RCM is criticised for being too time-consuming. Frequently this is because an organisation does not have the knowledge of its plant and equipment which RCM demands. This should not be perceived as an RCM deficiency: it is the fault of those within the company who are operating machines without fully understanding how they work, how they fail and what happens when they fail. RCM users pointed out an additional benefit of RCM: that the process has taught participants in the RCM implementation much about their plant and processes. The results have been spectacular in some instances, and have prevented catastrophic disasters in other cases. It is easy to say that such problems would have been picked up without RCM, but the reality is that equipment is often operated and maintained incorrectly for years. The discipline imposed by RCM makes people think beyond the narrow (and incorrect) definition of maintenance as preventing failures. Ensuring functionality ensures that the design parameters are related to performance, and vast sums are not wasted on trying to prevent failures which occur, in reality, because designs are inadequate, or machines are too small, or plant is operated incorrectly.

It is understandable that managers are only really interested in techniques which reduce costs, but new maintenance thinking suggests a broader outlook. Just as low cost products are but one strategic possibility, so maintenance must think further than cost. If cost is the overriding criterion, then management is obliged to create systems which will measure and provide measurable information on costs. The concept of cost must in any event be broadened. One of the most crucial items in maintenance management is the cost effectiveness of maintenance. Without precise figures for the cost of downtime, it is not possible to determine if scheduled preventive maintenance is cost effective. Several issues should be divorced from cost considerations, particularly safety and environmental matters (Moubray, 1997). 
The nature of failure, that is, how items fail, has been spoken about for decades. This refers in particular to the relationship between how old an item is and how likely it is to fail. The bath-tube curve is now widely accepted as a gross simplification of this relationship (Moubray, 1997; Smith, 1993). It is positively incorrect in many instances. A major cost saving by companies $\mathrm{A}, \mathrm{D}, \mathrm{H}$ and $\mathrm{J}$ has been to dispense altogether with annual shutdowns. They have managed to do this, but generally in the face of great resistance from the maintenance function, who still believe that we must have a look at least once a year. Such comments come from those same maintenance people who accept that with an increasing variety of assets there is no underlying relationship between failure probability and age of equipment, and that replacement at fixed intervals does nothing for the reliability of the system, and can even aggravate the situation.

Inappropriate intervals for scheduled replacement maintenance frequently arise because of inadequate history reporting systems. However, far more serious than this is the fallacious belief that condition monitoring intervals are determined by frequency of failure and severity of consequences. Lead time to failure is the way to decide how often to carry out condition monitoring tasks. History systems invariably do not contain such data, but that is no excuse for basing interval estimations on incorrect premises.

The TPM 'zero defects' philosophy must be seen in the context of operating circumstances. Allowing an item to fail may well be the cheapest option where, for example, standby facilities are available and no secondary damage is caused by failure (this, of course, assumes that maintenance efforts are directed to ensure appropriate availability of standby equipment, and there are methods [Moubray, 1997] for determining what appropriate availability means). Such thinking has forced managers to understand the precise nature of standby equipment: again this refers to the functionality of the entire system, rather than the narrow maintenance of individual subsystems or components.

With greater restructuring of departments, reducing supervisory levels and empowerment of individuals, maintenance is no longer a function on its own. New maintenance thinking means that maintenance intervention is determined by main. tenance in conjunction with production and technical deparments. 'Complete knowledge' can only be attained if maintenance staff work in conjunction with others who are closely involved with equipment. Joint ownership of maintenance solutions is essential, otherwise the battle between production and maintenance will perpetuate. The organisations in this study that have successfully introduced maintenance systems, such as RCM, TPM or MMIS, are adamant that necessary conditions for success are setting precise objectives, being absolutely clear in their minds as to what maintenance can and cannot achieve, and establishing systems for performance measurement.

From the theory and analysis presented in this article, it is possible to suggest some tentative conclusions by identifying factors critical for successful maintenance implementation. Figure 1 (a modification of the framework presented by Slevin \& Pinto, 1987) shows a sequence of initiatives and requirements which lead to successful implementation: in this case, improved and more cost effective asset performance. Figure 1 thus represents a preliminary attempt in analysing broad issues relating to physical asset management.

\section{Conclusion}

The management of physical assets must respond to rapidy changing maintenance challenges. While techniques and technology for maintenance improvement have been tried, the success of maintenance interventions has been limited, largely because of inadequate planning, incorrect implementation and poor measurement. Rather than being a traditional corporate burden, maintenance can help organisations achieve world class status. The challenge is to know what the new thinking is, and how to apply it. The purpose of this article has been to provide a new insight into world class physical asset management strategies.

\section{References}

Banerjee, A. \& Flynn, B.B. 1987. A simulation study of some maintenance policies in a group technology shop, International Journal of Production Research, 25: 1595-1609.

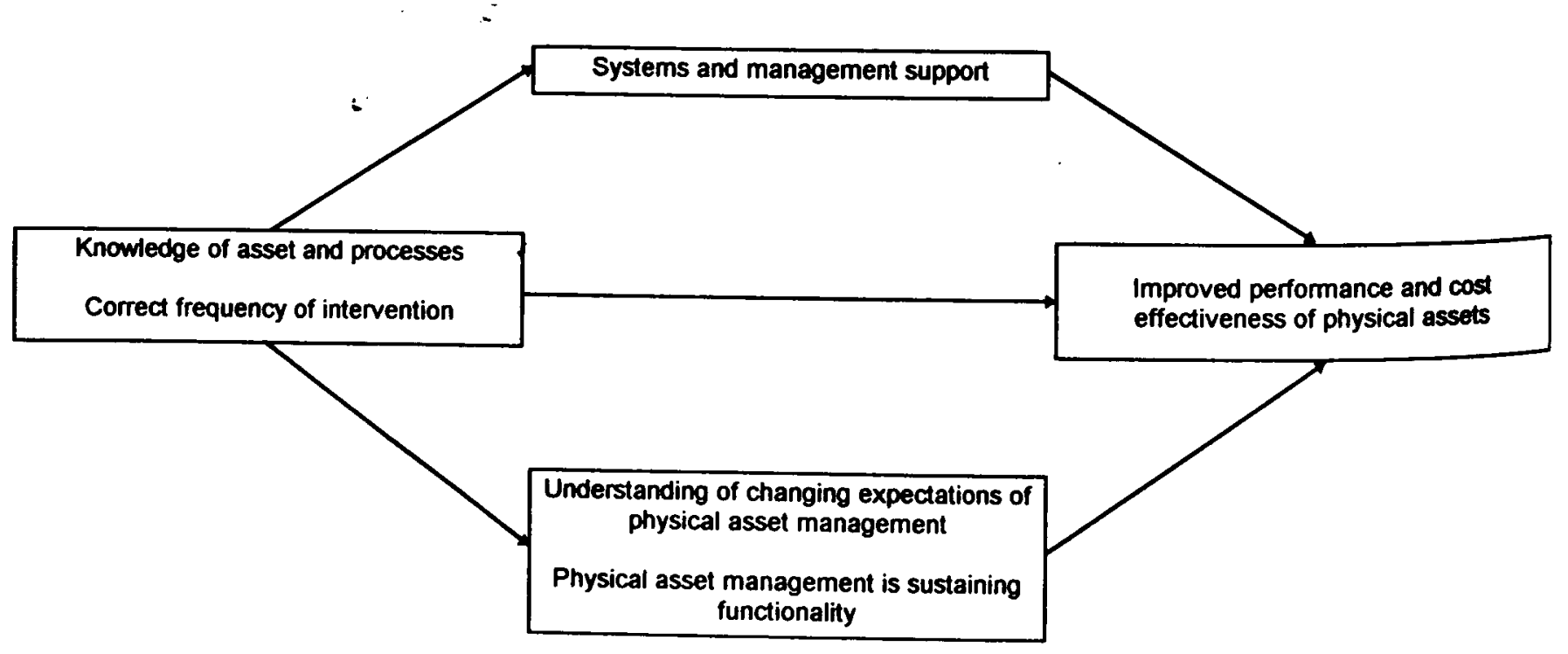

Figure I Sequence of factors for physical asset management 
Bennett. D.I. \& Jenney, B.W. 1980. Reliability: its implications in production systems and design. Omega. 8: 441)-443.

Bouche, M.. Plauchu, V. \& Retour, D. 1986. L.es nouveau enjeux de la maintenance, Revue française de la Gestion, 59:6-16.

Cho, D.I. \& Parlar, M. 1991. A survey of maintenance models for multi-unit systems, European Journal of Operations Research, 51: 1-23.

Christer, A.H. 1984. Operational research applied to industrial maintenance and replacement. In Eglese, R.W. \& Rand, G.K. eds. Developments in operational research. Oxford: Pergamon Press, pp. 31-58.

Cleveland, G.. Schroeder, R.G. \& Anderson, J.C. 1989. A theory of production competence, Decision Sciences, 20: 655-668.

Crawford, K.M., Blackstone, J.H. \& Cox, J.F. 1988. A study of JIT implementation and operating problems, International Journal of Production Research, 26: 1561-1568.

Currie, W.L. \& Sneddon, J.J.M. 1992. Managing AMT in a justin-time environment in the UK and Japan, British Journal of Management, 3: 123-136.

Doll, W.J. \& Vonderbremse, M.A. 1991. The evolution of manufacturing systems: towards the post-industrial enterprise, Omega, 21: 401-411.

Drucker, P.F. 1990. The emerging theory of manufacturing, Harvard Business Review, 90: 94-102.

Eisenhardt, K.M. 1989. Building theories from case study research, Academy of Management Review, 14: 532-550.

Ferdows, K. \& De Meyer, A. 1990. Lasting improvements in manufacturing performance: in search of a new theory, Journal of Operations Management, 9: 168-184.

Flynn, B.B., Sakakibara, S., Schroeder, R.G., Bates, K.A. \& Flynn, E.J. 1990. Empirical methods in operations management, Journal of Operations Management, 9: 250-284.

Gits, C.W. 1994. Structuring maintenance control systems, International Journal of Operations and Production Management. 14(7): 5-17.

Huber, G.P. 1984. The nature and design of post-industrial organizations, Management Science, 30: 928-951.
Jaikumar, R. 1986. Post-industrial manufacturing. Harvard Business Review, 64(6): 69-76

Leonard-Barton, D. 1987. Implementing structured software methodologies: a case of innovation in process technology. Interfaces, 17: 6-17.

Leonard-Barton, D. 1995. Wellsprings of knowledge. Boston: Harvard University Press, 335p.

McCutcheon, D.M. \& Meredith. J.R. 1987. Conducting case study research in operations management. Journal of Operations Management, 11: 239-256.

Meredith, J. 1987. Automating the factory, International Journal of Production Research, 25: 1493-1510.

Moubray, J. 1997. Reliability-centred maintenance. Oxford: Butterworth-Heinemann, 423p.

Nakajima, S. 1988. Introduction to Total Productive Maintenance. Cambridge, MA: Productivity Press. 129p.

Padmanabhan, V. \& Souder, W.E. 1994. A Brownian motion model for technology transfer: application to a machine maintenance expert system, Journal of Product Innovation Management, 11: 129-123.

Paz, N.M. \& Leigh, W. 1994. Maintenance scheduling: issues. results and research needs, International Journal of Operations and Production Management, 8: 47-69.

Safayani, F. \& Purdy, L. 1991. A behavioural case study of justin-time implementation, Journal of Operations Management. 10: 35-53.

Slevin D.P. \& Pinto, J.K. 1987. Balancing strategy and tactics in project implementation, Sloan Management Review, 33: 33-41.

Smith, A.M. 1993. Reliability-centered maintenance. New York: McGraw-Hill, 317p.

Turban, E. 1967. The use of mathematical models in plant maintenance decision making, Management Science, 13: 342-358.

Willmott, P. 1994. TPM the western way. London: Productivity Press, 253p.

Yin, R.K. 1989. Case study research: design and methods. Newbury: Sage, 354p. 